\title{
Прототип раздела эпидемиологического атласа «Мониторинг заболеваемости COVID-19»
}

Побединский Г. Г., Сарсков С, А., Вьюшков М. В.

ФБУН «Нижегородский научно-исследовательский институт эпидемиологии и микробиологии им. академика И. Н. Блохиной» Роспотребнадзора, Нижний

Новгород, Россия

Геоинформационное обеспечение мониторинга за инфекционными болезнями является одним из приоритетных научных направлений Федеральной службы по надзору в сфере защиты прав потребителей и благополучия человека (Роспотребнадзор). Опыт создания и эксплуатации электронного эпидемиологического атласа Приволжского федерального округа («Эпидемиологический атлас ПФО») подтвердил актуальность этого направления для обеспечения санитарно-эпидемиологического благополучия населения и востребованность результатов практическим звеном санэпидслужбы [1, 2]. В целях эффективного использования имеющегося опыта разработки и применения ГИС «Эпидемиологический атлас ПФО», дальнейшего ее совершенствования, расширения функций для применения в других федеральных округах специалисты лаборатории ГИС-технологий и биоинформатики ФБУН ННИИЭМ им. академика И. Н. Блохиной Роспотребнадзора (лаборатория ГИС-технологий) в 2019 г. приступили к выполнению НИР «Разработка территориально распределённого геоинформационного программного комплекса «Электронный эпидемиологический атлас Российской Федерации» (ГИС «Эпидемиологический атлас России») [2, 3, 4]. В соответствии с Концепцией создания ГИС «Эпидемиологический атлас России» предусмотрено два уровня реализации системы: окружной и федеральный и, соответственно, разработка двух подсистем. Подсистема ГИС «Эпидемиологический атлас России. Территория федерального округа» разрабатывается в рамках действующей НИР в соответствии с Отраслевой научно-исследовательской программой Роспотребнадзора на 20162020 гг. «Проблемно-ориентированные научные исследования в области эпидемиологического надзора за инфекционными и паразитарными болезнями». Разработка подсистемы ГИС «Эпидемиологический атлас России. Территория Российской Федерации» предполагается в рамках новой НИР в соответствии с в соответствии с Отраслевой научно-исследовательской программой Роспотребнадзора на 2021-2025 гг. [5]. Аналитический аппарат действующей ГИС «Эпидемиологический атлас ПФО» и проектируемой ГИС «Эпидемиологический атлас России» основан на наиболее часто встречающемся в эпидемиологии методе ретроспективного анализа случаев инфекционной заболеваемости, фиксируемых в системе федерального статистического наблюдения. К сожалению этот метод слабо применим для анализа текущего эпидемического процесса, такого как обострение ситуации с заражением геморрагической лихорадкой с почечным синдромом (ГЛПС) в Приволжском федеральном округе в 2019 г., ситуации с пандемией короновируса COVID-19 в 2019-2020 гг. В настоящей 
статье кратко рассмотрены экспериментальные работы по оперативному мониторингу заболеваемости COVID-19 в Нижегородской области.

В соответствии с обращением заместителя руководителя Управления Роспотребнадзора по Нижегородской области Н. А. Садыковой № 52-00-08/063696-2020 от 13.05.2020 лаборатория ГИС-технологий в рамках НИР по созданию ГИС «Эпидемиологический атлас России» приступила к экспериментальной работе по организации и проведению картографического учета в геоинформационной системе инфицированных COVID-19 лиц по месту жительства (без указания квартир) в оперативном режиме. Институт дополнительно проинформировал Управление о необходимости направлять сформированные данные на электронную почту лаборатории ГИС-технологий и биоинформатики lab.gis@nniiem.ru в формате Microsoft Excel для оперативного учета. В настоящее время завершена разработка прототипа раздела эпидемиологического атласа «Мониторинг заболеваемости COVID-19» и осуществляется размещение данных, представляемых Управлением. Размещены данные о 24,7 тыс. инфицированных COVID-19 по Нижегородской области, в том числе январь - 2, февраль - 2, март 141, апрель - 2446, май - 946, июнь - 17414, июль - 3712. Ввод данных, представляемых Управлением, продолжается. Доступ к прототипу раздела атласа: http://epid-atlas.nniiem.ru/atlas3/.

В локальную базу данных «Мониторинг заболеваемости COVID-19» включены следующие данные: координаты места нахождения инфицированного, описание места локализации, включающее наименование области, района, населенного пункта, улицы, эпидномер, дата заболевания и дата подтверждения. Координаты места нахождения инфицированного определяются по почтовому адресу (без указания квартир) с использованием функции геокодирования. Визуализация данных осуществляется с использованием модуля картографического отображения для работы с базой данных на основе библиотеки Leaflet.js., которая является программным обеспечением с открытым исходным кодом. Функциональность модуля была протестирована на основных современных браузерах: Firefox, Chrome, Safari, Opera, IE9+, Android and iOS. B качестве картографической основы используется открытые картографические сервисы OpenStreetMap и GRAY.

Модуль картографического отображения позволяет осуществить выбор картографической основы, выбор месяца (или группы месяцев), изменение масштаба отображения, группировку инфицированных при уменьшении масштаба, вывод на экран справочной информации при нажатии на условное обозначение инфицированного, вывод на экран названия района (функция востребована при увеличении масштаба отображения). Примеры работы прототипа раздела эпидемиологического атласа «Мониторинг заболеваемости COVID-19» приведены на рис. 1, 2. 
Мониторинг заболеваемости Covid-19

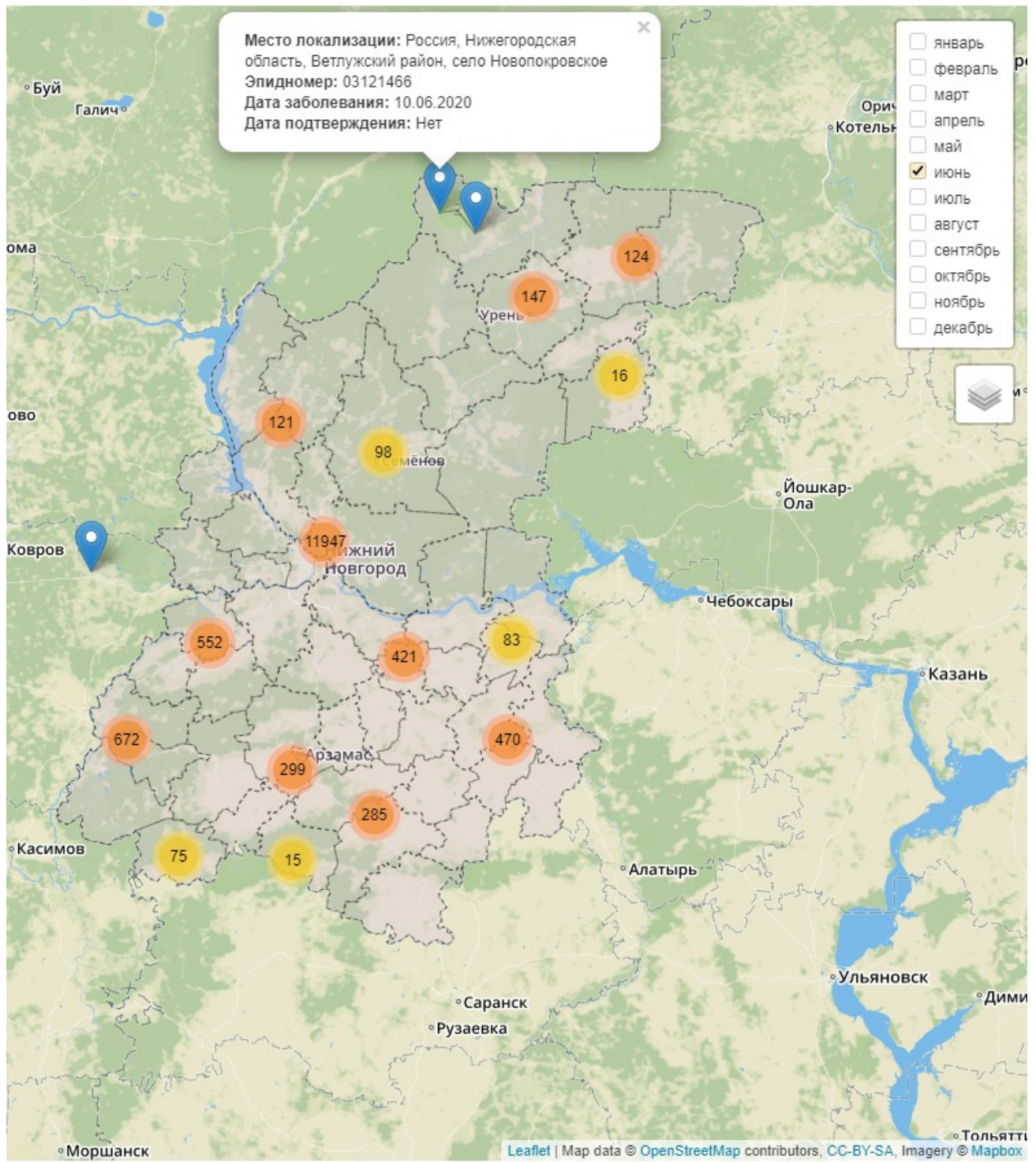

Рис. 1. Пример картографического отображения заболеваемости COVID-19» в июне 2020 г. по Нижегородской области 


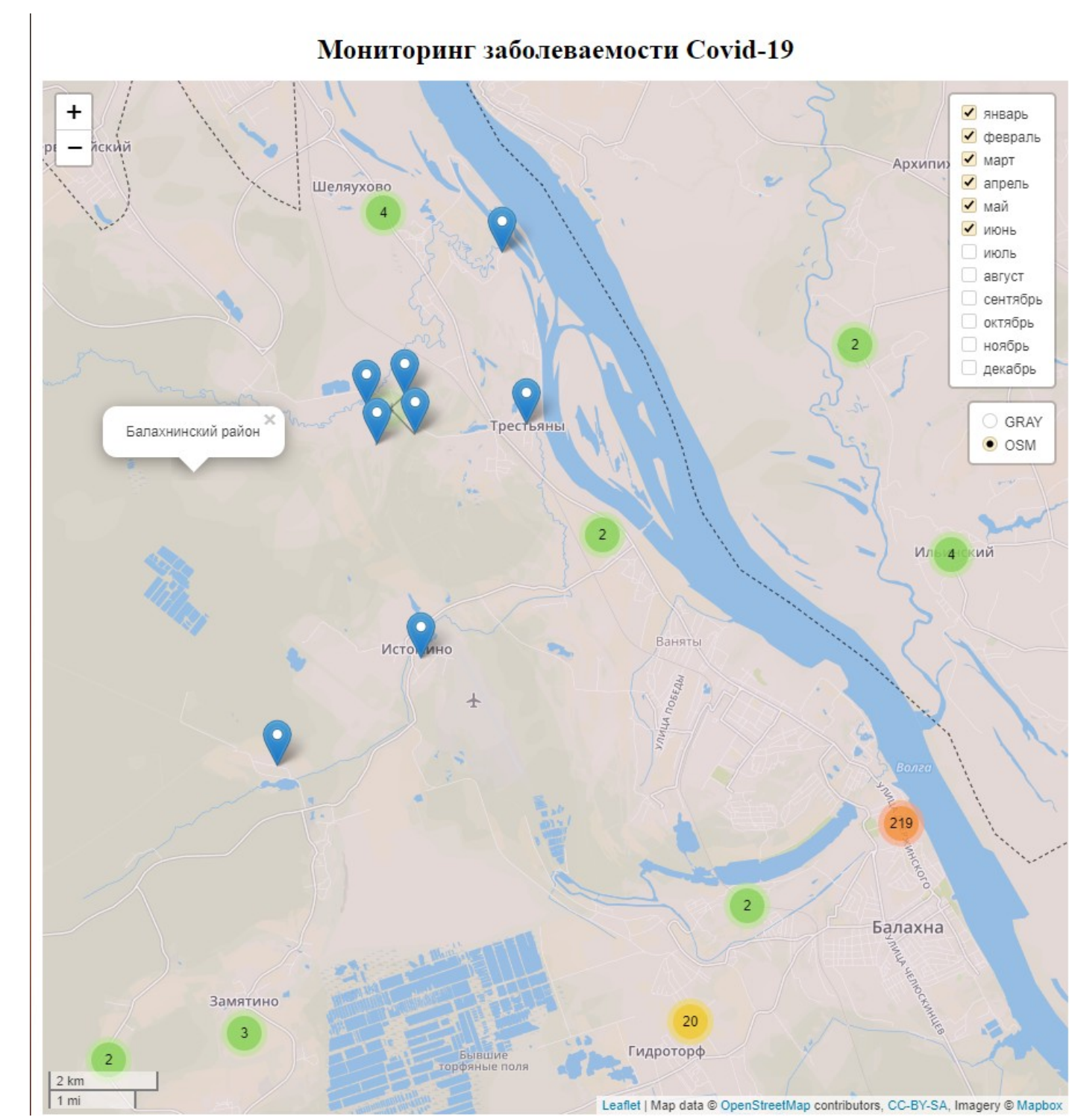

Рис. 2. Пример картографического отображения заболеваемости COVID-19» в январе - июне 2020 г. по Балахнинскому району Нижегородской области

В соответствии с поручением А. Ю. Поповой от 5.06.2020 о проведении мониторинга и анализа эпидситуации по заболеваемости COVID-19 подготовлены предложения по дополнению содержания планируемых на 2021 - 2025 гг. работ в рамках НИР «Разработка территориально распределенного геоинформационного программного комплекса «Эпидемиологический атлас Российской Федерации. Территория Российской Федерации» разработкой дополнительного тематического раздела атласа «Мониторинг заболеваемости COVID-19».

При этом в рамках действующей в 2019-2020 гг. НИР «Разработка территориально распределенного геоинформационного программного комплекса «Электронный эпидемиологический атлас Российской Федерации. Территория федерального округа» проработать с Управлениями Роспотребнадзора по субъектам Российской Федерации в Приволжском федеральном округе вопрос координации представления информации об инфицированных COVID-19 лицах по согласованной форме. 
Применение ГИС является весьма эффективным инструментом обеспечения мониторинга здоровья населения. На сегодняшний день существует ряд работ по визуальному (картографическому) отображению ситуации, связанной с COVID19. Одним из ярких примеров является работа европейского бюро ВОЗ «Ситуация с COVID-19 в Европейском регионе BO3» [6].

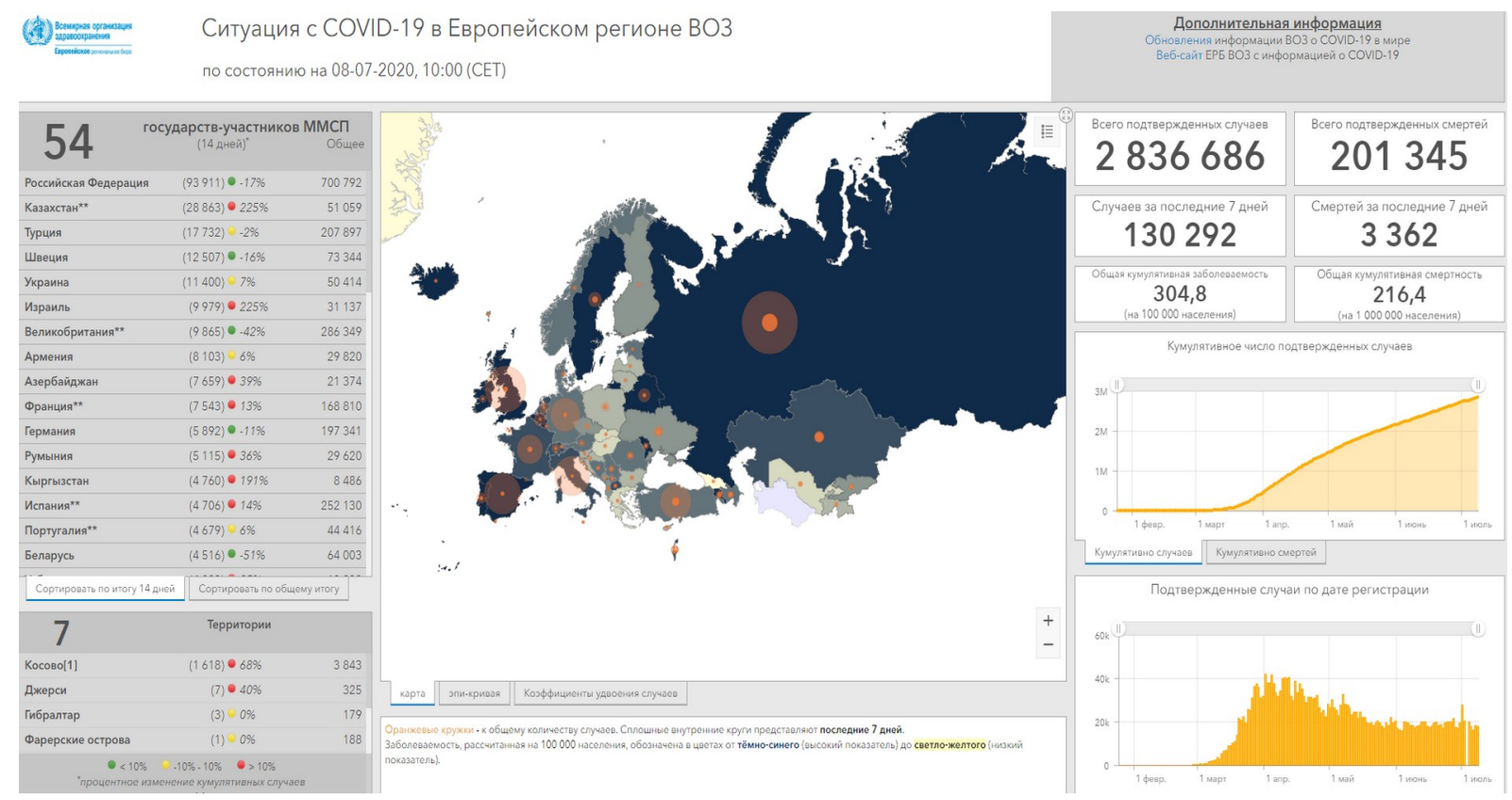

Рис. 3. Пример картографического отображения заболеваемости COVID-19 на сайте европейского бюро ВО3 [6]

Территориальный охват - страны Европы Система условных знаков на тематической карте в основном представлена привязанными к государственным границам площадными условными знаками в виде заливок различного цвета и интенсивности и пунсонами различного диаметра в центре региона. При наведении курсора на конкретный регион подсвечивается граница и всплывает наименование страны и краткая информация по заболеваемости в целом по стране из легенды карты.

Другим примером является картографическое представление случаев заболеваний и смерти в США на официальном сайте Центров по контролю и профилактике заболеваний Министерства здравоохранения и социальных услуг США. (Centers for Disease Control and Prevention (CDC) of the U.S. Department of Health and Human Services) [7]. 


\section{Cases by Jurisdiction}

This map shows COVID-19 cases reported by U.S. states, the District of Columbia, New York City, and other U.S.affiliated jurisdictions. Hover over the maps to see the number of cases reported in each jurisdiction. To go to a jurisdiction's health department website, click on the jurisdiction on the map.
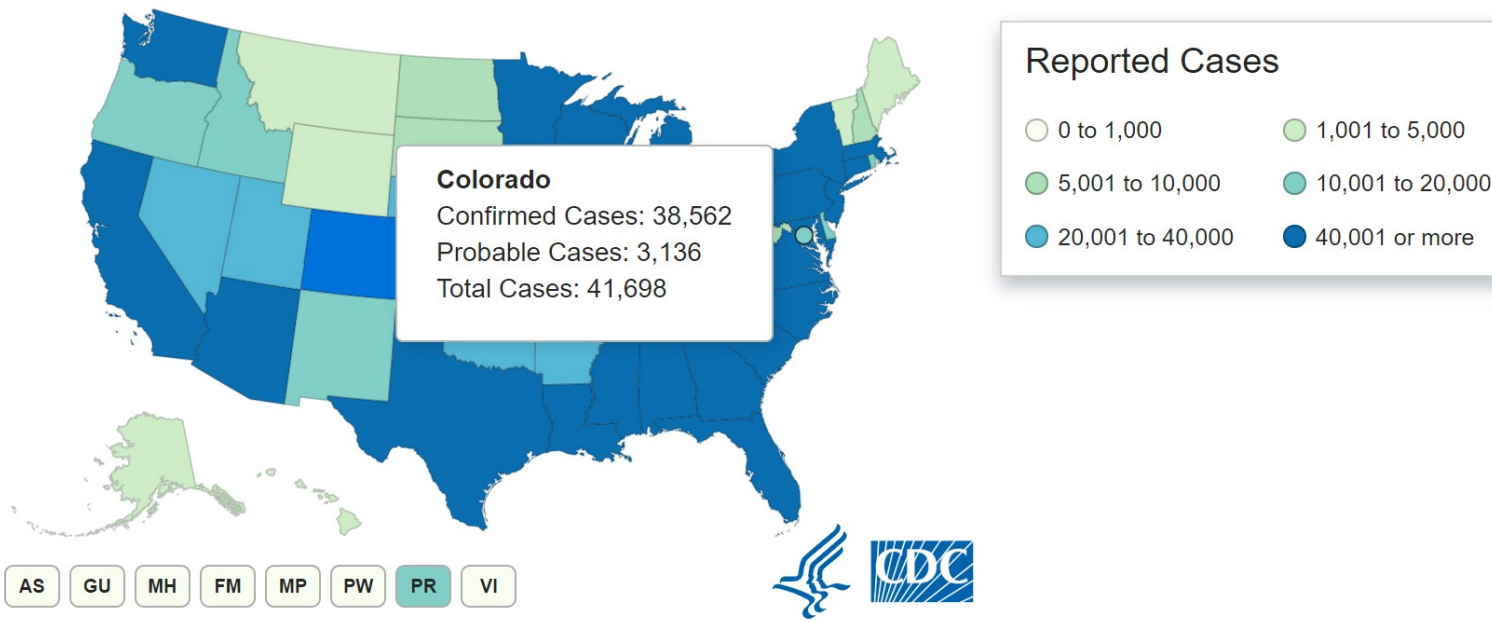

Рис. 4. Пример картографического отображения заболеваемости COVID-19 на сайте CDC (США) [7].

\section{Deaths by Jurisdiction}

This map shows COVID-19 cases reported by U.S. states, the District of Columbia, New York City, and other U.S.affiliated jurisdictions. Hover over the maps to see the number of deaths reported in each jurisdiction. To go to a jurisdiction's health department website, click on the jurisdiction on the map.

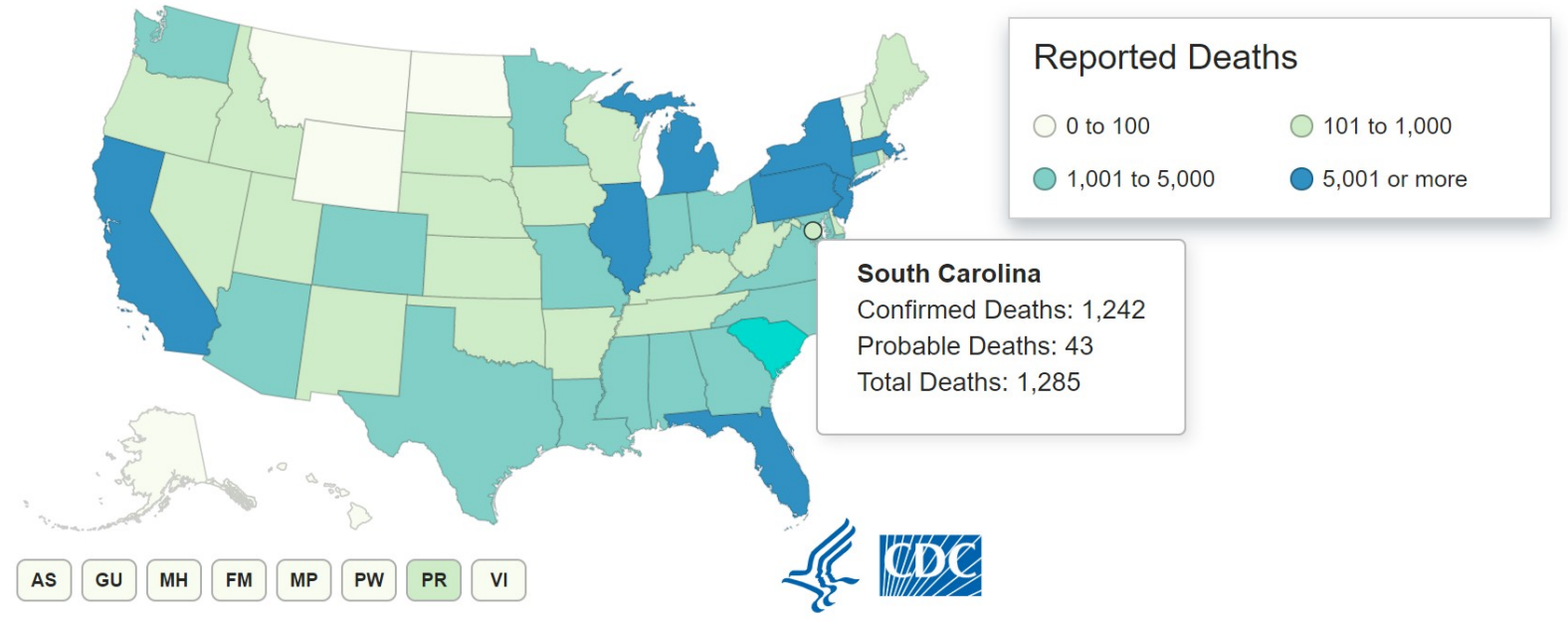

Рис. 5. Пример картографического отображения смертности COVID-19 на сайте CDC (CША) [7].

На этих картах показаны случаи заболевания и смерти COVID-19, о которых сообщили штаты, округ Колумбия, Нью-Йорк и другие юрисдикции, связанные с США. При наведении курсора на конкретный штат, всплывает число случаев заболевания и случаев смерти, зарегистрированных в каждой юрисдикции.

Среди отечественных примеров отображения ситуации, связанной с COVID-19, необходимо отметить работу сайта Яндекс карты «Карта распространения коронавируса в России и мире» [8]. 


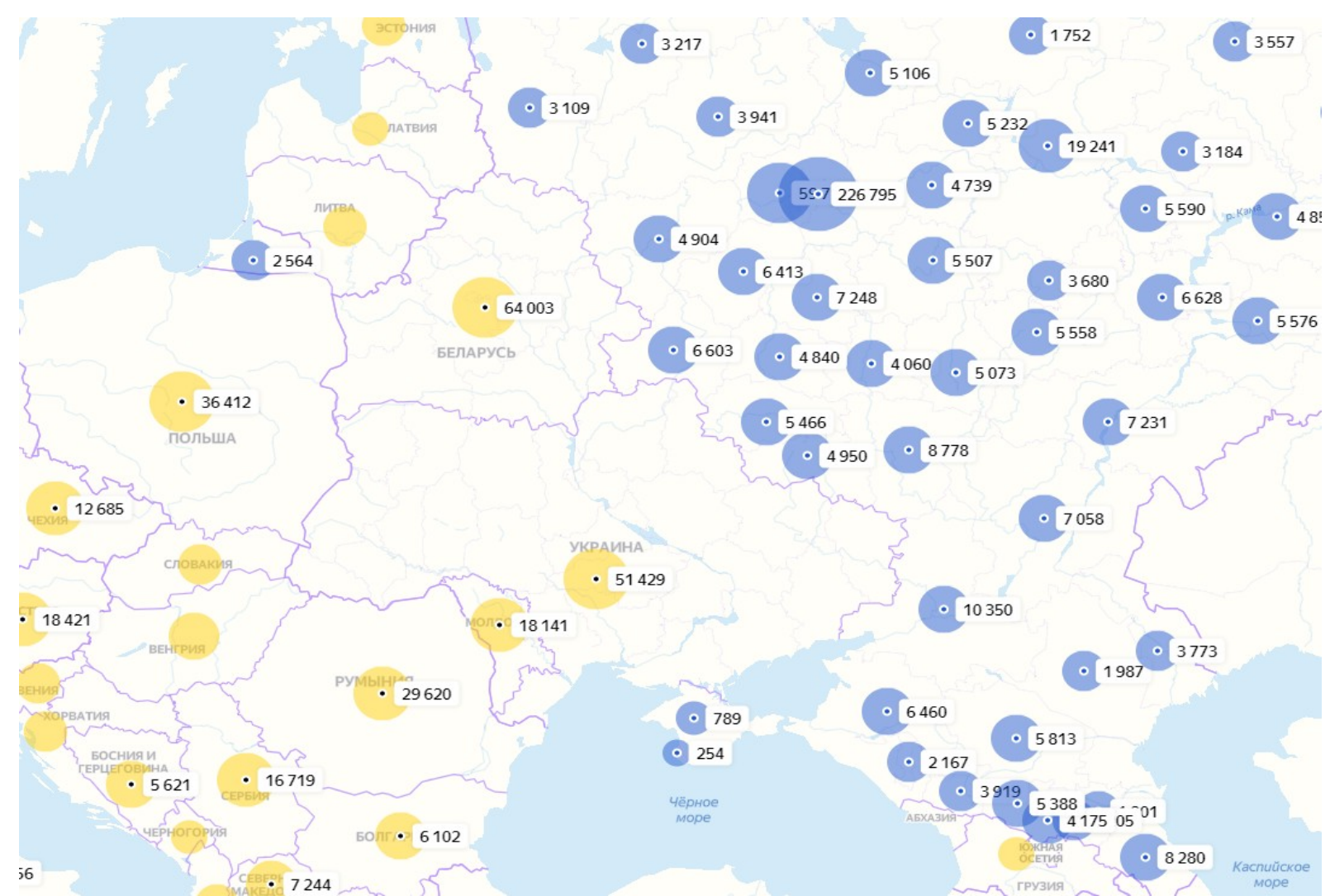

Рис. 6. Пример картографического отображения заболеваемости COVID-19 на сайте Яндекс карты [8].

Территориальный охват - страны мира и регионы России. Система условных знаков на тематической карте в основном представлена привязанными к государственным и региональным границам точечными условными знаками в виде пунсонов различного диаметра в центре региона. При наведении курсора на конкретный пунсон региона всплывает наименование страны/региона и краткая информация по числу заболевших, выздоровевших и умерших в целом по стране из легенды карты.

Аналогичная информация представлена на сайте Коронавирус-монитор интерактивная карта распространения и статистика Covid-19 [9] (рис. 7).

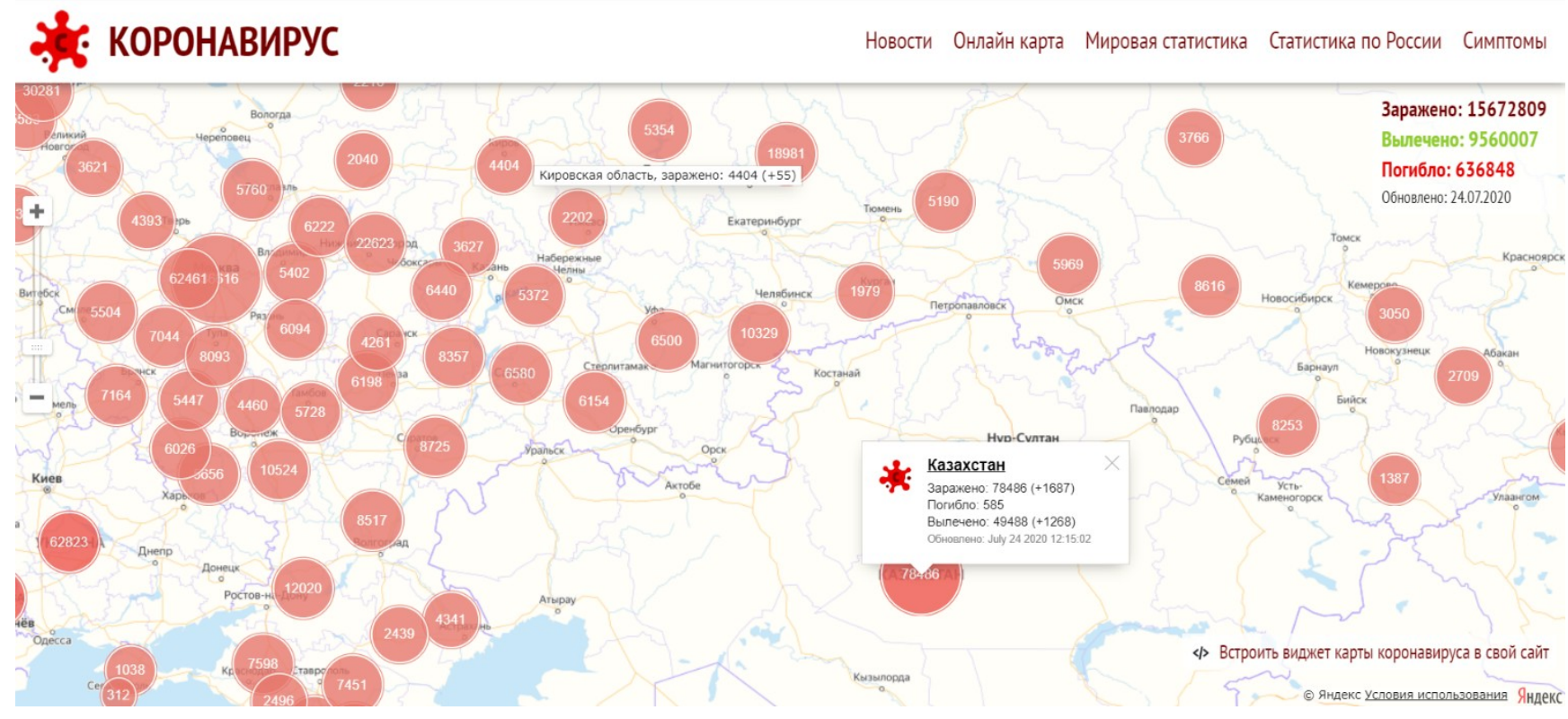


Рис. 7. Пример картографического отображения заболеваемости COVID-19 на сайте Коронавирус-монитор [9].

Примером картографического отображения обобщенного количества случаев заражения COVID-19 по административно-территориальным единицам Российской Федерации, является онлайн-карта распространения коронавируса по городам и районам Нижегородской области, представленная на сайте газеты «Нижегородская правда» [10].

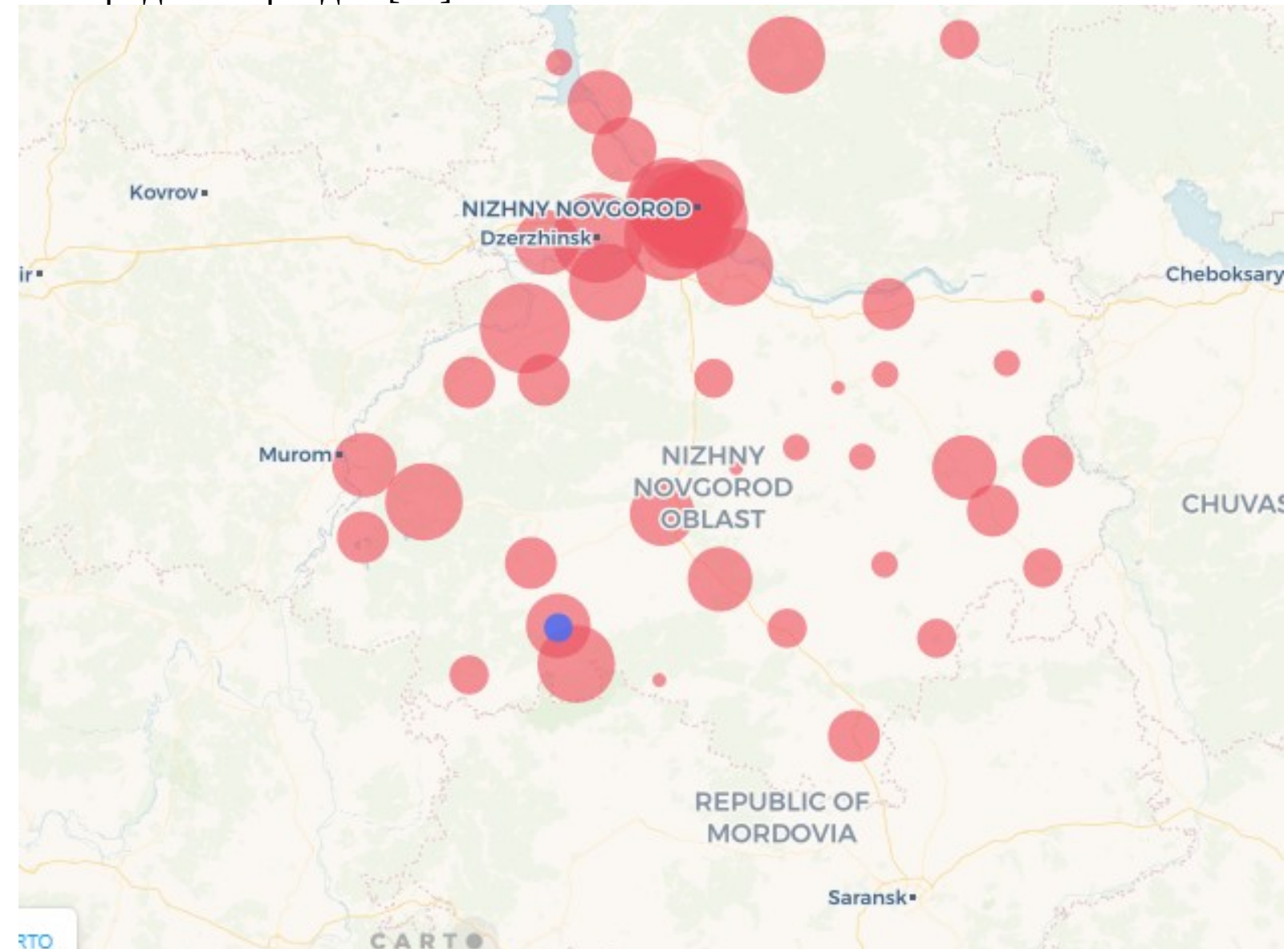

Рис. 8. Пример картографического отображения заболеваемости COVID-19 на сайте газеты «Нижегородская правда» [10].

Территориальный охват - Нижегородская область. Система условных знаков на тематической карте представлена привязанными к административным границам точечными условными знаками в виде пунсонов различного диаметра в центре региона. При наведении курсора на конкретный пунсон региона всплывает наименование региона и количество подтвержденных случаев COVID-19.

Аналогичная информация представлена на сайте В городе N [11] (рис. 9). 


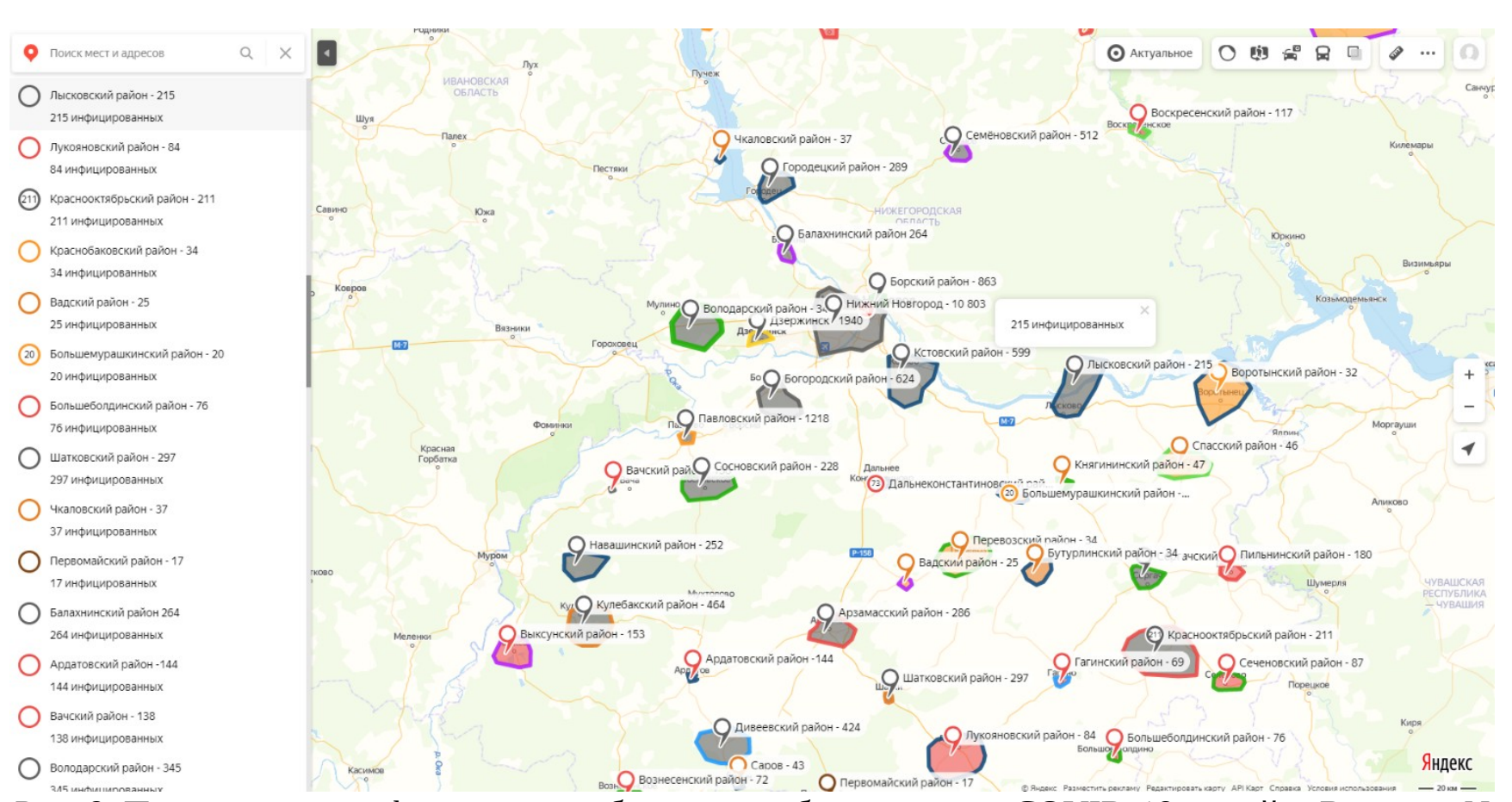

Рис. 9. Пример картографического отображения заболеваемости COVID-19 на сайте В городе N [11].

Bсе представленные примеры объединяет способ предоставления информации, а именно, отображение на картографической основе общего количество случаев заболевания в стране, регионах страны или административнотерриториальных образованиях. Отличительной особенностью разрабатываемого в рамках ГИС «Эпидемиологический атлас Российской Федерации» тематического раздела атласа «Мониторинг заболеваемости COVID-19» является предоставление информации с детализацией до улицы и дома, что дает возможность оценивать эпидемиологическую ситуацию в конкретной местности, знать активные эпидемиологические очаги и проводить на основе оперативного эпидемиологического анализа необходимые санитарно-эпидемиологические мероприятия.

\section{Литература}

1. Электронный эпидемиологический атлас Приволжского федерального округа [Электронный ресурс]. - Режим доступа: http://epid-atlas.nniiem.ru/ (дата обращения: 24.07.2020).

2. Ершов В. И., Ефимов Е. И., Побединский Г. Г. Опыт разработки и ведения ГИС «Электронный эпидемиологический атлас Приволжского федерального округа» / Здоровье населения и среда обитания. 2019. № 8 (317). - с. 11 - 19. DOI: $\quad$ 10.35627/2219-5238/2019-317-8-11-19. $\quad$ https://elibrary.ru/item.asp? $\underline{\mathrm{id}=39275403}$

3. Побединский Г. Г., Сарсков С. А. Медицинская география. Современное состояние и направления развития / 21-й Международный научнопромышленный форум «Великие реки'2019». Труды научного конгресса. В 3 т. T. 1. - Нижний Новгород: ННГАСУ, 2019. - с. 272 - 281. ISBN 978-5-528-003603;

978-5-528-00361-0.

https://cloud.mail.ru/stock/bs5fREwpnAcMmwyGB6tzXXM7. 
http://www.nngasu.ru/about/cooperation/ForumXXI.php.

https://elibrary.ru/item.asp?id=41146619

4. Ефимов Е. И., Побединский Г. Г. О новой концепции Эпидемиологического атласа. / 20-й Международный научно-промышленный форум «Великие реки'2018». Труды научного конгресса. В 3 т. Т. 1. - Нижний Новгород: ННГАСУ, 2018. - с. 304 - 309. ISBN 978-5-528-00299-6; 978-5-528-00300-9. http://www.nngasu.ru/word/reki2018/velikie-reki-2018-1.pdf. https://elibrary.ru/item.asp?id=36316643

5. Разработка методических подходов к созданию ГИС «Эпидемиологический атлас России» [Текст]: отчет о НИР (промежут.): / ФБУН ННИИЭМ им. академика И. Н. Блохиной; рук. Е. И. Ефимов. - Нижний Новгород, 2019. 116 с. - исполн. Г. Г. Побединский, В. И. Ершов, М. В. Вьюшков, С. А. Сарсков, Ю. Р. Белых. - Библиогр.: с.38 - 43. - № ГР АААА-Б19219120590046-7. [Электронный ресурс]. - Режим доступа: https://rosrid.ru/ikrbs/ 9GZMA2RJ4KYAZND5D7ZQIKKT (дата обращения: 24.07.2020). https://elibrary.ru/item.asp?id=41681676

6. Ситуация с COVID-19 в Европейском регионе BO3. [Электронный ресурс]. Режим доступа: https://who.maps.arcgis.com/apps/opsdashboard/index.html\#/a19d5d1f86ee4d99b01 3eed5f637232d (дата обращения: 24.07.2020).

7. Coronavirus Disease 2019 (COVID-19) [Электронный ресурс]. - Режим доступа: https://www.cdc.gov/coronavirus/2019-ncov/cases-updates/cases-in-us.html (дата обращения: 24.07.2020).

8. Карта распространения коронавируса в России и мире. [Электронный ресурс]. - Режим доступа: $\quad$ https://yandex.ru/maps/covid19?

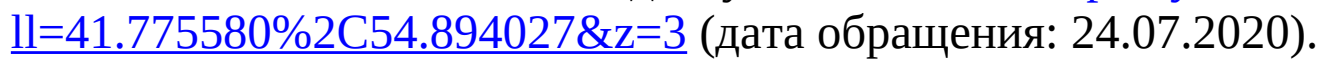

9. Коронавирус-монитор - интерактивная карта распространения и статистика Covid-19. [Электронный ресурс]. - Режим доступа: https://coronavirusmonitor.info/ (дата обращения: 24.07.2020).

10.Онлайн-карта распространения коронавируса по городам и районам Нижегородской области. [Электронный ресурс]. - Режим доступа: https://pravda-nn.ru/news/opublikovana-onlajn-karta-rasprostraneniya-koronavirusapo-gorodam-i-rajonam-nizhegorodskoj-oblasti/ (дата обращения: 24.07.2020).

11.Карта заразившихся коронавирусом в Нижегородской области. [Электронный ресурс]. - Режим доступа: https://www.vgoroden.ru/mesta/mesto/kartazarazivshihsya-koronavirusom-v-nizhegorodskoy-oblasti (дата обращения: 24.07.2020). 